\title{
Complementary effects of HDAC inhibitor 4-PB on gap junction communication and cellular export mechanisms support restoration of chemosensitivity of PDAC cells
}

\author{
O Ammerpohl', A Trauzold', B Schniewind', U Griep', C Pilarsky², R Grutzmann², H-D Saeger², O Janssen ${ }^{3}$, \\ B Sipos ${ }^{4}$, G Kloppel $^{4}$ and $H$ Kalthoff ${ }^{*}, 1$
}

'Section Molecular Oncology, Clinic for General Surgery and Thoracic Surgery, University Hospital Schleswig-Holstein Campus Kiel, Arnold-Heller Strasse 7, Kiel 24 105, Germany; ${ }^{2}$ Department of Visceral, Thoracic and Vascular Surgery, University Hospital Carl Gustav Carus, Technical University of Dresden, Dresden 01 307, Germany; ${ }^{3}$ Institute of Immunology, University Hospital Schleswig-Holstein Campus Kiel, Kiel 24 I05, Germany; ${ }^{4}$ Institute of Pathology, University Hospital Schleswig-Holstein Campus Kiel, Kiel 24105, Germany

Pancreatic ductal adenocarcinoma (PDAC) is a fatal disease and one of the cancer entities with the lowest life expectancy. Beside surgical therapy, no effective therapeutic options are available yet. Here, we show that 4-phenylbutyrate (4-PB), a known and welltolerable inhibitor of histone deacetylases (HDAC), induces up to 70\% apoptosis in all cell lines tested (Panc I, T4M-4, COLO 357, $\mathrm{BxPc} 3)$. In contrast, it leads to cell cycle arrest in only half of the cell lines tested. This drug increases gap junction communication between adjacent T3M-4 cells in a concentration-dependent manner and efficiently inhibits cellular export mechanisms in Panc I, T4M-4, COLO 357 and BxPc3 cells. Consequently, in combination with gemcitabine 4-PB shows an overadditive effect on induction of apoptosis in BxPc3 and T3M-4 cells (up to 4.5-fold compared to single drug treatment) with accompanied activation of Caspase 8, $\mathrm{BH} 3$ interacting domain death agonist (Bid) and poly (ADP-ribose) polymerase family, member I (PARP) cleavage. Although the inhibition of the mitogen-activated protein kinase-pathway has no influence on fulminant induction of apoptosis, the inhibition of the JNK-pathway by SP600I 25 completely abolishes the overadditive effect induced by the combined application of both drugs, firstly reported by this study.

British Journal of Cancer (2007) 96, 73-81. doi:10.1038/sj.bjc.66035II www.bjcancer.com

Published online 12 December 2006

(c) 2007 Cancer Research UK

Keywords: HDAC inhibitor; 4-phenylbutyrate; gemcitabine; pancreatic carcinoma

Patients with pancreatic ductal adenocarcinoma (PDAC) still suffer from a very poor prognosis. Pancreatic ductal adenocarcinoma is ranked fourth among the cancer-related death in the US, responsible for approximately 31000 deaths per year and the overall 5-year survival rate is less than $5 \%$. Despite major progress in medical science during the last decades, the annual cancer-related death rate for PDAC has not changed significantly during these decades (Jemal et al, 2005). Additionally, therapies proven to be successful for treating many other tumour entities, failed in PDAC treatment.

Deregulated genes in PDAC have been published recently by us and others (Crnogorac-Jurcevic et al, 2002; Iacobuzio-Donahue et al, 2003; Logsdon et al, 2003; Grutzmann et al, 2004). These genes included candidates involved in cell cycle control, apoptosis, cell motility or other tumour relevant pathways, but druggable key players have to be defined yet. Thus, new therapies for PDAC are urgently required. Because given gene therapy, directly addressing

\footnotetext{
*Correspondence: Dr H Kalthoff; E-mail: hkalthoff@email.uni-kiel.de Revised 6 November 2006; accepted 7 November 2006; published online 12 December 2006
}

single deregulated genes, still suffers from inefficient gene transfer and tumour targeting, we focused on other drugs like histone deacetylases (HDAC) inhibitors, generally influencing the activity of deregulated genes by changing the chromatin status. Acetylation of histones is associated with gene activation, whereas deacetylation mediated by HDAC is associated with gene silencing, classifying $\mathrm{HDAC}$ as a powerful drug target (Yoshida et al, 2001). Inhibitors of HDAC modulate chromatin structure resulting in loosening of the chromatin and changing transcription factor loading to the DNA (Nakano et al, 1997).

This modulates the expression pattern of various tumour relevant genes for the control of the cell cycle or apoptosis (Huang et al, 2000; Kim et al, 2004) causing inhibition of cell growth and differentiation (Feinman et al, 2002; Svechnikova et al, 2003; Yokota et al, 2004).

4-phenylbutyrate (4-PB) is one of few histone deacetylase inhibitors (HDACi) already tested in clinical trials in the treatment of recurrent malignant gliomas or the myelodysplastic syndrome (Bhalla and List, 2004; Phuphanich et al, 2005). Additionally, it is a FDA-approved and well-tolerated drug for urea cycle disorders (Rubenstein and Zeitlin, 1998), therefore being an attractive candidate for other therapies. 
Gemcitabine is a widely used drug in the treatment of several cancer entities, including lung, breast and pancreatic carcinoma. Gemcitabine belongs to the antimetabolites interfering with the cell cycle progression. In several studies gemcitabine was combined with other established anticancer drugs like 5-FU, cisplatin, docetaxel and radiotherapy to address or to overcome the extraordinary resistance of pancreatic carcinoma to chemotherapy (Eisenberg et al, 2005; Ko and Tempero, 2005; Pipas et al, 2005).

In this study, we investigated the effect of 4-PB as a single drug on various cancer-related parameters like proliferation, induction of apoptosis and intercellular communication in several PDAC cell lines. Furthermore, although comparing the effects of single drug treatment with gemcitabine and 4-PB, we show overadditive effects in a combined treatment with both drugs. This study provides a comprehensive insight into the effects and advantages of the use of the HDACi 4-PB in the treatment of PDAC. Additionally, for the first time, we could show synergistic effects when combining 4-PB treatment with gemcitabine, a classical chemotherapeutical drug.

\section{MATERIALS AND METHODS}

\section{Cell culture}

Pancreatic carcinoma cell lines COLO 357, Panc 1, T3M-4; BxPc3 (Sipos et al, 2003) and primary human fibroblasts were grown as described (Grutzmann et al, 2004). HPDE6-E6E7-c7 cells (H6c7) (Furukawa et al, 1996; Ouyang et al, 2000) were grown in a medium containing FCS (10\%, PAN Biotech, Aidenbach, Germany), RPMI 1640 (45\%), Keratinocyte-SFM (45\%), Bovine Pituitary Extract $\left(25 \mathrm{mgl}^{-1}\right)$ and hEGF $\left(2.5 \mu \mathrm{gl}^{-1}\right.$, all Invitrogen, Karlsruhe, Germany). Cells were treated with 4-PB (Triple Crown America, dissolved in phosphate-buffered saline (PBS)), JNK inhibitor II (SP600125; Calbiochem, Merck, Darmstadt, Germany) or zVAD (Bachem, Weit am Rhein, Germany) as indicated. Cell counting was performed using a CASY1 TT-cell counter (Schärfe System, Reutlingen, Germany) according to the manufacturer's instruction.

\section{Isolation of human PBMC}

Peripheral blood mononuclear cells (PBMC) were isolated by Ficoll-Hypaque density gradient centrifugation of buffy coat preparations obtained from healthy blood donors. T-cell blasts were generated from unseparated PBMC in the presence of phytohemagglutinin (PHA $0.5 \mu \mathrm{g} \mathrm{ml}^{-1}$, Murex Biotech Ltd, Abbott, Wiesbaden, Germany). After 3 days, dead cells were removed by Ficoll density gradient centrifugation and T-cell blasts were expanded in RPMI 1640 with 5\% FBS, antibiotics, L-glutamine and HEPES supplemented with $50 \mathrm{U} \mathrm{ml}^{-1}$ rIL-2 (Chiron Behring, Novurtis, Marburg, Germany). Cells were kept at $37^{\circ} \mathrm{C}$ in a humidified atmosphere with $5 \% \mathrm{CO}_{2}$. For cytotoxicity/viability assays, freshly isolated PBMC or PHA blasts (day 14) were incubated for $20 \mathrm{~h}$ with or without gemcitabine $\left(1.0 \mu \mathrm{g} \mathrm{ml}^{-1}\right)$ in the presence or absence of different concentrations of 4-PB from 0.5 to $5.0 \mathrm{~mm}$. FACS analysis was performed as described below.

\section{Cell cycle analysis and accompanied apoptosis measurement}

After two washes with PBS, cells were trypsinised, pelleted, resuspended in PBS containing $5 \mathrm{~mm}$ EDTA and fixed by adding one volume of ethanol (Merck). After RNase-treatment (40 ng RNaseA $\mu \mathrm{l}^{-1}$, Sigma-Aldrich, Munich, Germany) cells were pelleted, resuspended in PBS containing propidium iodide $\left(200 \mu \mathrm{g} \mathrm{ml}^{-1}\right)$ and subjected to FACS analysis. Cell cytometry was conducted using a FACScan cell analyzer (Becton-Dickinson Bioscience, Heidelberg, Germany). WinMDI2.8 (http://facs.scripps. edu) was used for analysing FACS data.

\section{Gap junction communication}

Subconfluent cells were trypsinised, pelleted, resuspended in RPMI 1640 medium and divided into equal portions. Two samples were treated either without or with $1.0 \mathrm{~mm}$ or $5.0 \mathrm{~mm} 4-\mathrm{PB}$, respectively. Additionally, one of the corresponding cell portions was treated with calcein-AM (Molecular Probes, Invitrogen, Karlsruhe, Germany) at a concentration of $67 \mathrm{nM}$. After $40 \mathrm{~min}$ at $37^{\circ} \mathrm{C}$, cells were washed three times in PBS and the corresponding portions treated with identical $4-\mathrm{PB}$ concentrations were combined and plated onto a cell culture vessel. After $5 \mathrm{~h}$ additional incubation at $37^{\circ} \mathrm{C}$, cells were trypsinised, washed, resuspended in PBS and analysed by FACS analysis.

Samples containing only unstained or stained cells served as a control and were also used for validating staining of the cells.

\section{Multi drug resistance}

Cells were treated without or with $2.0,5.0,10.0 \mathrm{~mm} 4-\mathrm{PB}$ or $100 \mu \mathrm{M}$ verapamil for up to $72 \mathrm{~h}$. Then, Calcein-AM was added to a final concentration of $100 \mathrm{~nm}$ to the medium. After $2 \mathrm{~h}$, cells were trypsinised, washed two times and resuspended in PBS. The intracellular accumulation of the dye was determined by cell cytometry (Karaszi et al, 2001).

\section{Apoptosis assays}

The JAM assay was performed as described previously (Ungefroren et al, 1998). In some cases, apoptosis was also measured using ApoAlert annexin- $\mathrm{V}$ binding assay (Clontech, SaintGermain-en-Laye, France) according to the manufacturer's protocol.

\section{Histone deacetylase activity assay}

BxPc3 and T3M-4 cells untreated or treated with $2.0 \mathrm{~mm} 4-$ phenylbutyrate for $48 \mathrm{~h}$ were released by trypsinisation and washed in PBS. After centrifugation, the cell pellet was resuspendet in PBS and cells were lysed by three cycles of freezing and thawing followed by sonification. The HDAC activity in the supernatant was determined using the Histone Deacetylase Activity Assay Kit, colorimetric (Calbiochem) according to the manufacturer's instruction.

\section{Western blot analysis}

Western blot analysis was performed as described before (Trauzold et al, 2003). Primary antibodies used were purchased from different companies as indicated: anti-PARP-mab (Ab-2, Calbiochem), anti-Caspase 8 (StressGen Biotechnology, Biomol, Hamburg, Germany), anti-Bid (R\&D Systems, WiesbadenNordenstadt, Germany), anti- $\beta$-actin (Sigma-Aldrich), anti-phospho JNK and anti-JNK (Cell Signaling, Danvers, MA, USA).

\section{Computer based analysis}

T-test; ANOVA analysis and graphical presentations were performed using GraphPad Prism version 4.02. for Windows (GraphPad Software). Photoshop CS (Adobe) was used for preparing microscopic photos.

\section{RESULTS}

\section{4-phenylbutyrate inhibits HDAC activity in pancreatic cancer cells}

To verify the assumed inhibitory effect of 4 -PB on the HDAC activity in pancreatic cancer cells, we determined the HDAC 


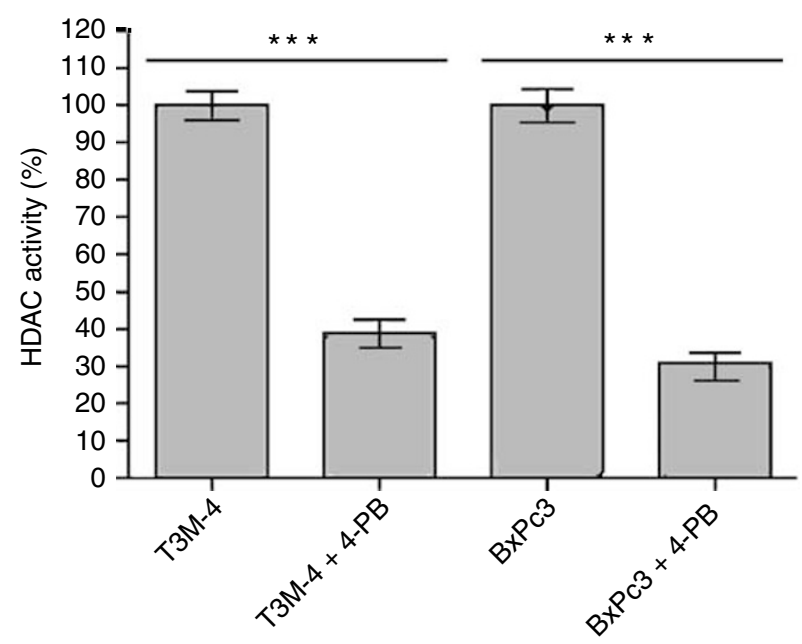

Figure I 4-phenylbutyrate inhibits HDAC activity in pancreatic cancer cell lines. T3M-4 and BxPc3 cells were untreated or treated with $2.0 \mathrm{~mm} 4-$ PB for $48 \mathrm{~h}$. Histone deacetylases activity of untreated cells was determined colorimetrically and set to 100\%. The relative HDAC activity in treated cells was calculated. Results from five measurements are presented (mean \pm s.e.m). The observed inhibition proved to be highly significant ( $t$-test; $P<0.000$ I) activity in T3M-4 and BxPc3 cells treated with the drug and compared the results with an untreated control. After $48 \mathrm{~h}$ of treatment, even concentration of $4-\mathrm{PB}$ as low as $2.0 \mathrm{~mm}$ led to a $60-70 \%$ decrease in HDAC activity in both cell lines (Figure 1). Thus, 4-PB has a tremendous effect on the activity of the HDAC activity in pancreatic cancer cells.

\section{4-phenylbutyrate treatment inhibits growth and induces apoptosis of ductal pancreatic adenocarcinoma cells}

To study the influence of 4-PB on PDAC cells, we analysed growth, morphology and viability of T3M-4, BxPc3, COLO 357 and Panc 1 cells treated with different concentrations of 4-PB for up to $72 \mathrm{~h}$. By counting cell numbers, we found that 4-PB significantly reduced cell growth in a dose-, time- and cell line-dependent manner (Figure 2). Whereas even low concentrations of 4-PB (1.0 mM) strongly inhibited growth of T3M-4, BxPc3, Panc 1 and COLO 357 cells, primary cultures of human diploid fibroblasts that grew very slowly appeared much less sensitive to 4-PB treatment. Concentrations up to $10.0 \mathrm{~mm}$ did not essentially influence number of these cells even after $72 \mathrm{~h}$ of treatment (Figure 2). Performing an ANOVA test, the correlation of the decrease in cell number and the concentration of 4-PB was found to be extremely significant for all pancreatic tumour cell lines $(P<0.0001)$. Microscopical analyses revealed clear changes in the morphology of all pancreatic tumour
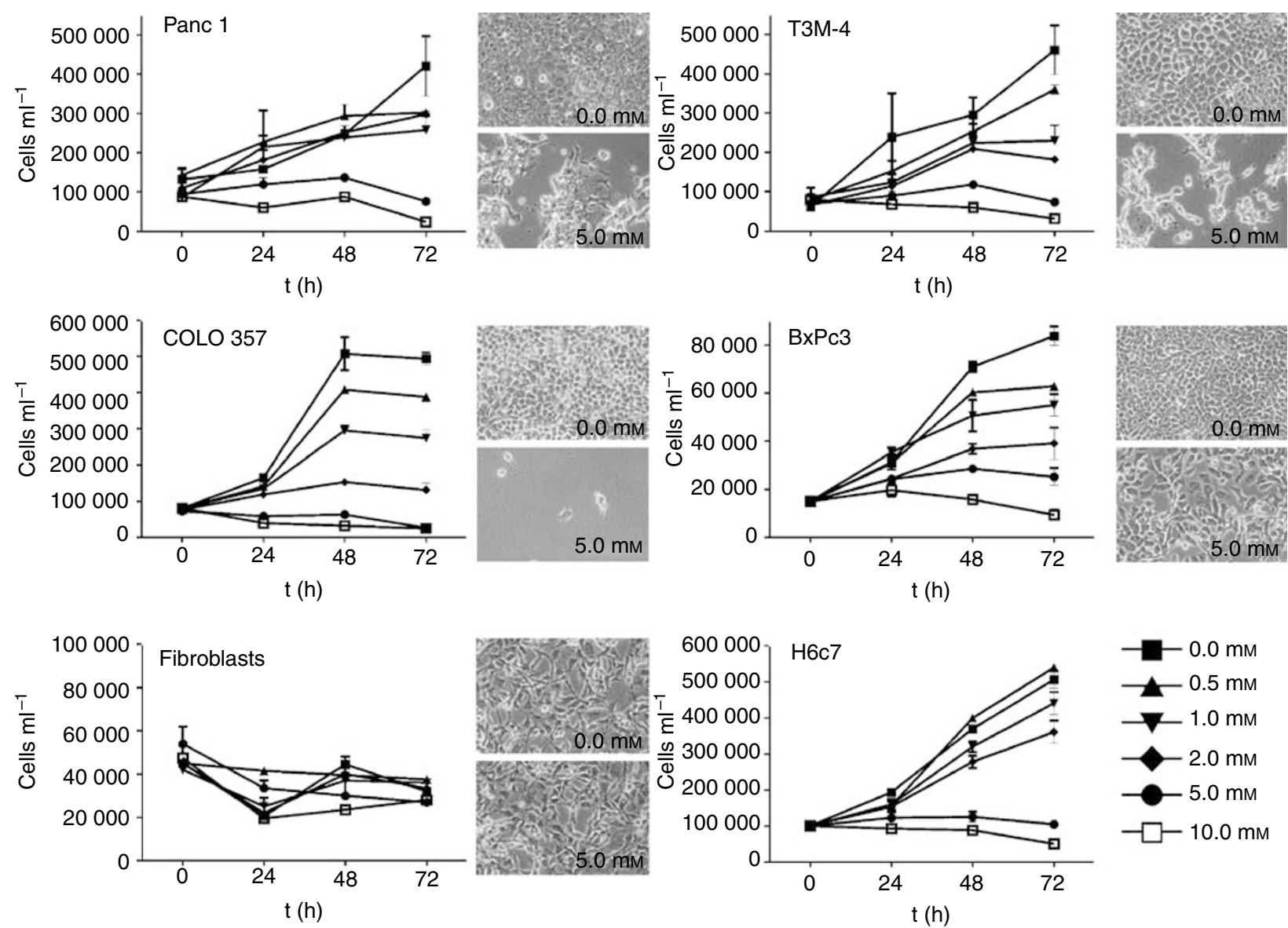

Figure 2 4-phenylbutyrate reduced cell number of pancreatic carcinoma cell lines in vitro. Panc I, T3M-4, COLO 357, BxPc3, primary human fibroblasts or $\mathrm{H} 6 \mathrm{c} 7$ cells were cultivated in the absence (black square) or presence of increasing 4-PB concentrations ( $0.5 \mathrm{~mm}$ (triangle), I.0 mM (inverted triangle), $2.0 \mathrm{mM}$ (diamond), $5.0 \mathrm{~mm}$ (circle)) up to $10.0 \mathrm{~mm}$ (white square). After 0, 24, 48 and $72 \mathrm{~h}$, the cell number per I ml medium was determined from every sample by cell counting using the CASYI TT-cell counter. Mean and s.e.m from at least three experiments are presented. To document morphological changes, a photo from each cell line taken after $48 \mathrm{~h}$ of treatment with $5.0 \mathrm{~mm}$ 4-PB (lower photo) and a corresponding untreated control (upper photo) is presented, respectively. 
cells tested (Figure 2), indicating cell death already $48 \mathrm{~h}$ after treatment with 4 -PB. In contrast to human fibroblasts that remained unaffected in this regard, human pancreatic ductal epithelial cell line $\mathrm{H} 6 \mathrm{c}$, which is rapidly growing comparable to the cancer cell lines is sensitive to $4-\mathrm{PB}$ treatment when the concentration of the drug exceeds $2.0 \mathrm{~mm}$.

As 4-PB-mediated growth inhibition could reflect induction of cell death or cell cycle arrest, we performed propidium iodide staining of cells treated for $48 \mathrm{~h}$ with increasing concentrations of 4 -PB and analysed the percentage of cells in sub-G1 phase of the cell cycle.

As shown in Figure 3A, 4-PB increased the number of cells in sub-G1 in all cell lines tested in a concentration-dependent manner. COLO 357 cells appeared most sensitive. Forty-eight hours exposition to $4-\mathrm{PB}$ concentrations as low as $2.0 \mathrm{~mm}$ led to death of approximately $30 \%$ of these cells and more than $70 \%$ died when exposed to $10.0 \mathrm{~mm}$ 4-PB. Although Panc 1, BxPc3 and T3M-
4 cells were more resistant to 4-PB treatment, higher 4-PB concentrations, for example, $10.0 \mathrm{~mm}$ also resulted in significant cell death. To prove mechanisms of cell death, we performed cell cytometry with Panc 1 cells and COLO 357 cells treated with 4-PB with or without pre-incubation with the broad spectrum caspase inhibitor zVAD-fmk. As shown in Figure 3B, cell death was significantly reduced in the presence of $\mathrm{zVAD}$, indicating that the observed cell death was apoptotic. In parallel, cell cycle analysis showed a concentration-dependent cell cycle arrest of T3M-4 and COLO 357 cells. This arrest could not be demonstrated for Panc 1 and BxPc3 cells (Figure 3A), even after prolonged incubation times of $72 \mathrm{~h}$. Thus, cell cycle arrest is no prerequisite for the induction of apoptosis. In contrast, normal mononuclear cells isolated from peripheral blood of human donors showed only weak response to treatment up to $5.0 \mathrm{~mm} 4$ $\mathrm{PB}$ (Figure 5C and data not shown), underlining the tolerance of non-malignant cells for 4-PB.
A
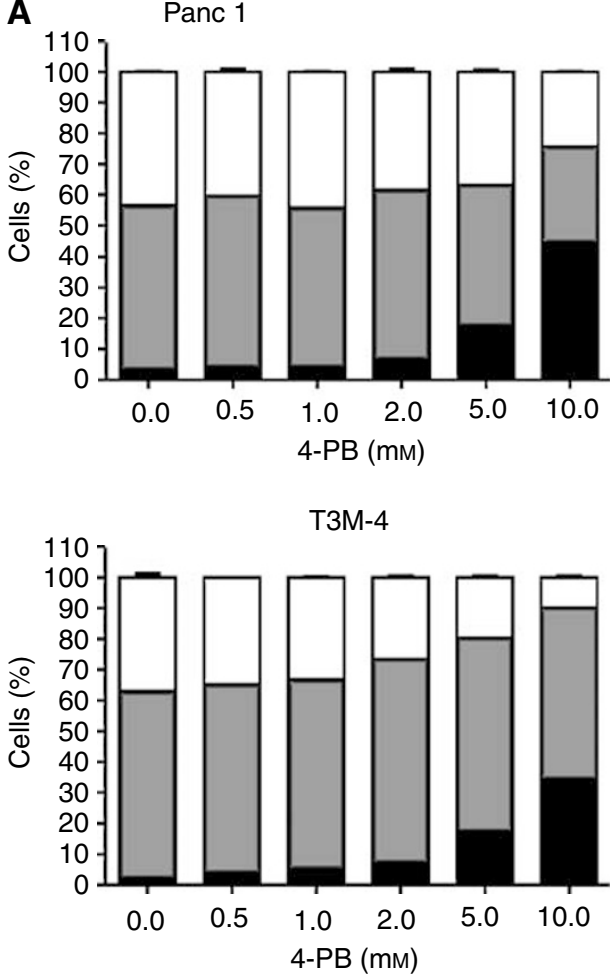

B

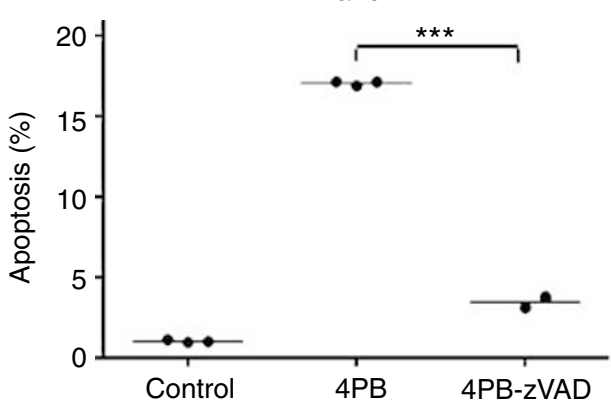

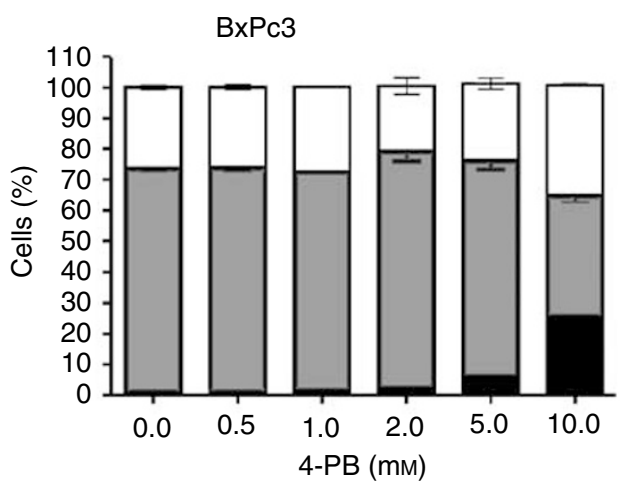

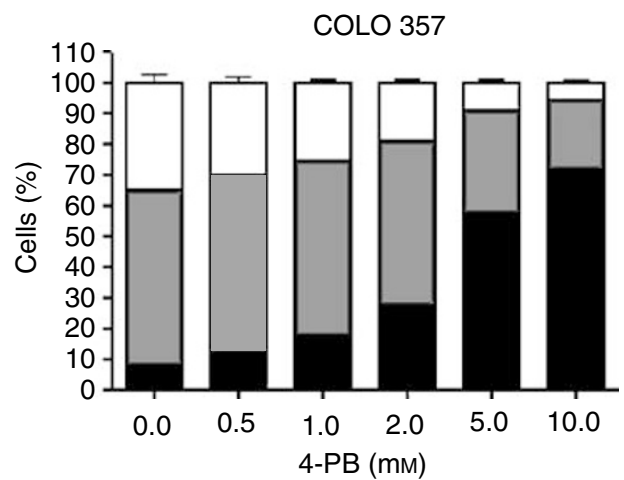

COLO 357

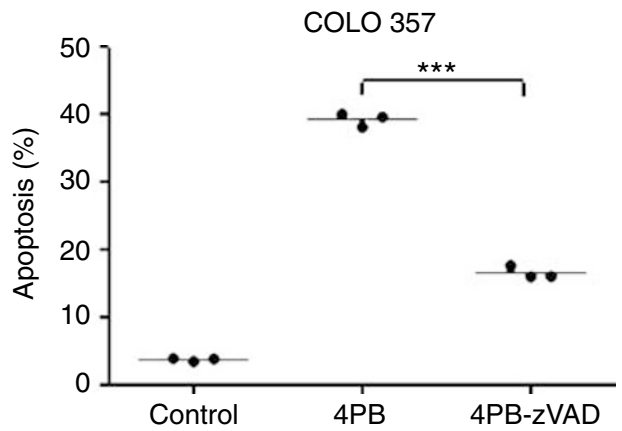

Figure 3 4-phenylbutyrate induced apoptosis and cell cycle arrest of pancreatic cell lines in a concentration-dependent manner. (A) Panc I, BxPc3, T3M4 and COLO 357 cells were treated with different concentrations of 4-PB for $48 \mathrm{~h}$. Cells were trypsinised and stained with propidium iodide. The percentages of apoptotic cells (black), cells in GI-phase (grey) or S- and G2-phase (white) were determined by flow cytometry. The mean from at least three samples is presented. (B) ZVAD inhibited 4-PB induced apoptosis. Panc I and COLO 357 cells were treated either with 5.0 mM 4-PB alone or a combination of $5.0 \mathrm{~mm} 4-\mathrm{PB}$ and $23 \mu \mathrm{g} \mathrm{ml}^{-1} \mathrm{zVAD}$ for $72 \mathrm{~h}$. Cells were trypsinised and stained with propidium iodide. The percentage of apoptotic cells was determined by flow cytometry. Prism 4 was used to perform $t$-test analysis. Effects of zVAD treatment proved to be highly significant $(P<0.000 \mathrm{I})$. 


\section{4-phenylbutyrate increased intercellular communication} between pancreatic carcinoma cells

In order to investigate intercellular communications of adjacent tumour cells, T3M-4 cells were labelled with calcein. After trypsinising and washing, cells were plated onto unlabelled cells of the same origin. Calcein loaded cells can attach to and transfer the dye into non-labelled cells via gap junctions (Asklund et al, 2004). Because the concentration of the dye in these afore unstained cells (now 'intermediately stained cells', Figure 4A) is lower than in the prelabelled cells, their fluorescence is also weaker. Thus, these cells can be identified by flow cytometry. When the tumour cells were cultured in the presence of 4 - $\mathrm{PB}$ for $24 \mathrm{~h}$ preceding and during the dye transfer, the intercellular dye transfer was enhanced. Although $1.0 \mathrm{mM}$ 4 -PB induced dye transfer only marginally after $5 \mathrm{~h}$ of co-culture, it nearly tripled dye transfer at a concentration of $5.0 \mathrm{~mm}$. Figure $4 \mathrm{~A}$ shows a typical outcome of the experiment conducted three times.

\section{4-phenylbutyrate inhibits cellular export mechanisms in a concentration-dependent manner}

One reason for the poor response of PDAC to chemotherapy is the drug resistance achieved by membrane protein pumps (Glavinas et al, 2004) developed by this cancer. In order to investigate the effect of 4-PB on cellular efflux and to identify possible benefits of a combinatorial treatment with other chemotherapeutics, the ability of cancer cells to export calcein-AM added to the cell culture medium was determined by flow cytometry. If this ability of the cell is reduced, calcein-AM accumulates in the cell and becomes a substrate of cellular esterases. The product of this enzymatic reaction, calcein, is a strong fluorescent. Thus, the fluorescence intensity of a cell inversely correlates with the cellular export (Karaszi et al, 2001). Pancreatic carcinoma cell lines Panc 1, BxPc3, T3M-4 and COLO 357 were treated with 0.0, 2.0, 5.0 or $10.0 \mathrm{~mm} 4-\mathrm{PB}$ or $100 \mu \mathrm{M}$ verapamil, a known inhibitor of MDR1-mediated efflux (Hindenburg et al, 1987) as a control to assure an adequate experimental design. Although Panc 1 cells only showed a response to $10.0 \mathrm{~mm} 4-\mathrm{PB}$ after $72 \mathrm{~h}$ of treatment and this maximum response was comparable to verapamil treatment, $\mathrm{BxPc} 3, \mathrm{~T} 3 \mathrm{M}-4$ and $\mathrm{COLO} 357$ responded already to lower doses of 4-PB, COLO 357 even much stronger than to verapamil (Figure 4B). Interestingly, the effect of the drug on cellular export increases even more with the time of treatment (data not shown). These results demonstrated that cellular export mechanisms of pancreatic carcinoma cell lines can be effectively influenced by $4-\mathrm{PB}$.
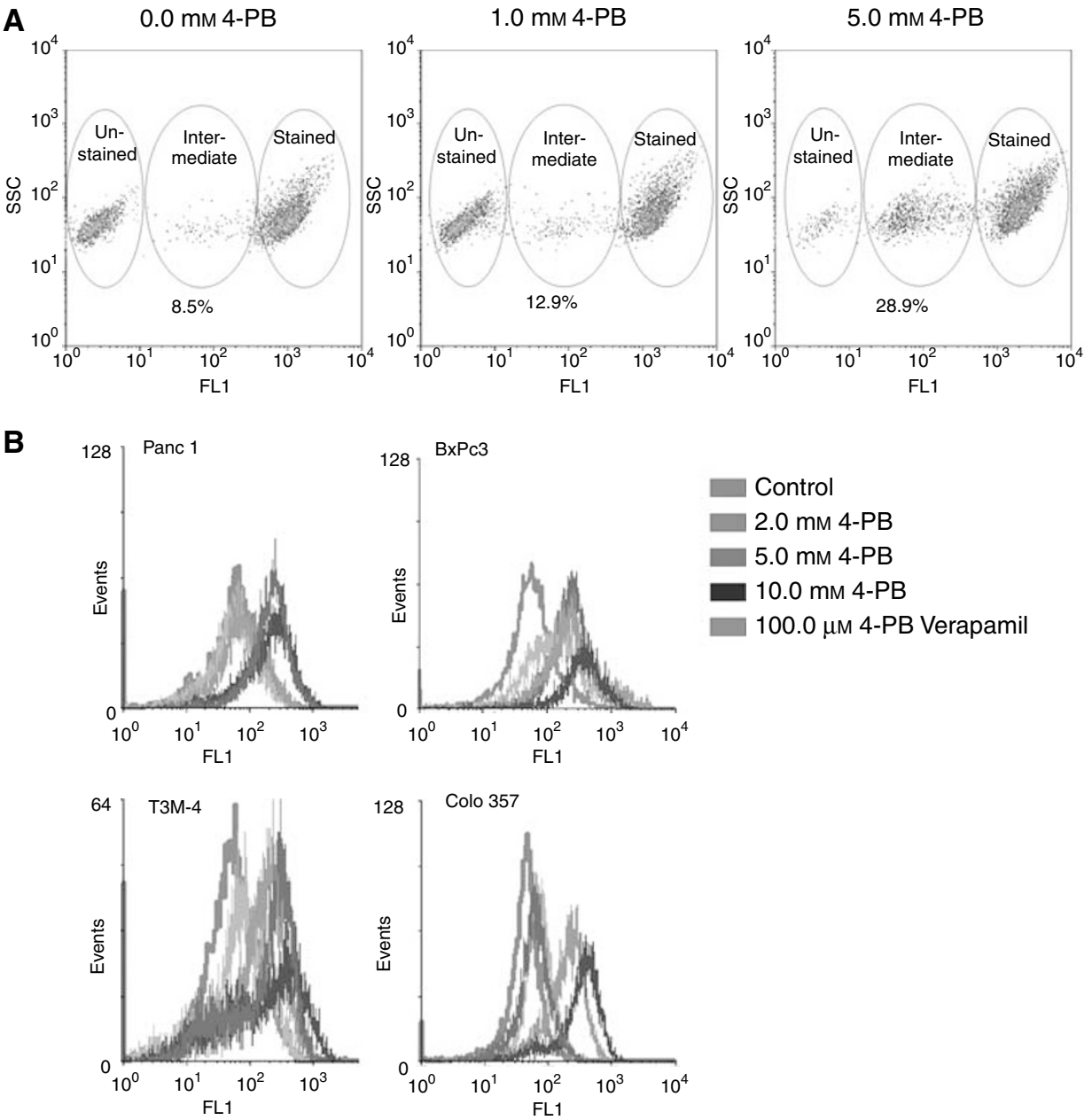

Figure 4 4-phenylbutyrate reduced cellular export and increased intercellular communication. (A) Pancreatic carcinoma cells either untreated, treated with $2.0 \mathrm{~mm}$ 4-PB, $5.0 \mathrm{~mm}$ 4-PB, $10.0 \mathrm{~mm}$ 4-PB or $100.0 \mu \mathrm{M}$ verapamil for $72 \mathrm{~h}$ were stained with Calcein-AM. The dye export was visualised by flow cytometry. The cellular export of calcein-AM was decreased by applying 4-PB in a dose-dependent manner (increase in fluorescence intensity) (B) CalceinAM stained and unstained T3M-4 cells were co-cultured in the absence or presence of 4-PB (I,0 mM or 5,0 mM 4-PB as indicated) for $5 \mathrm{~h}$. Cell cytometry was performed to distinguish unstained from calcein-AM stained cells. In the presence of 4-PB, the number of intermediately stained cells increased (right panel), whereas the number of unstained cells was reduced, showing intercellular dye transfer. The number of cells involved in dye transfer was calculated (\% of 'intermediately' stained cells). 


\section{4-phenylbutyrate increases gemcitabine-mediated} apoptosis in pancreatic tumour cells

Gemcitabine is one of the currently used substances to treat pancreatic adenocarcinoma. However, it does not improve the long-term survival of the patients (Bengala et al, 2005; Gelibter et al, 2005). Here, we tested the influence of concomitant use of 4$\mathrm{PB}$ and gemcitabine on two resistant pancreatic adenocarcinoma cell lines T3M-4 and BxPc3. Using DNA-fragmentation assay (JAM, Figure 5A) as well as annexin V/propidium iodide staining (Figure 5B), we found that 4-PB strongly enhanced gemcitabineinduced apoptosis in both cell lines. As shown in Figure 5A, low dose of gemcitabine $\left(1.0 \mu \mathrm{g} \mathrm{ml}^{-1}\right)$ resulted in BxPC3 cells in only moderate cell death. Similarly, low dose of 4-PB (1.0 mM) only slightly induced cell death. Interestingly, concomitant treatment of cells with both, gemcitabine and 4-PB strongly enhanced the effects of each of the substances alone and over $60 \%$ (determined by JAM assay, Figure $5 \mathrm{~A}$ ) or $50 \%$ (FACS analysis, Figure $5 \mathrm{~A}$ ) of cells died after $48 \mathrm{~h}$ of treatment. Similar results were obtained with T3M-4 cells (Figure 5A and B). Higher doses of 4-PB $(2.0 \mathrm{~mm}$ and $5.0 \mathrm{mM}$ ) only slightly increased the sensitising effects (data not shown).

In contrast to PDAC cell lines, PBMC isolated from human donors and cultured in vitro were much less sensitive to the drug treatment and did not show a significant response to the combinatorial treatment compared to the single drug treatment (Figure 5C).

Western blot analyses (Figure 5D) of lysates prepared from cells treated with 4-PB, gemcitabine or with both agents demonstrate that 4-PB strongly enhanced gemcitabine-mediated Caspase 8- and Bid-cleavage as well as PARP-cleavage assayed as a marker for Caspase 3-activation (Figure 5D).

Interestingly, 4-PB treatment led in both cell lines to upregulation of the expression of Caspase 8 and Bid. No differences in the expression levels of Caspase 3, Caspase 2 and IAPs were found in 4-PB-treated cells compared to untreated controls.

Recently, it has been shown that in gemcitabine-sensitive pancreatic tumour cell lines PK-1 and PCI-43, the drug-mediated apoptosis required the activation of $\mathrm{p} 38$ mitogen-activated protein kinase (MAPK) (Habiro et al, 2004). Thus, we analysed the involvement of p38 as well as MEK and JNK in gemcitabinemediated apoptosis of $\mathrm{BxPc} 3-$ and $\mathrm{T} 3 \mathrm{M}-4$ cells that were only moderately sensitive to gemcitabine treatment. Using specific MAPK inhibitors, we found no influence of MEK or p38 on gemcitabine-mediated cell death in these cells (data not shown). In contrast, inhibition of JNK completely abolished the sensitising effect of 4-PB (Figure 5B). Western blot analyses revealed that treatment of both cell lines with gemcitabine led to an increased JNK activity, the effect that was strongly enhanced by $4-\mathrm{PB}$ (Figure 5D).
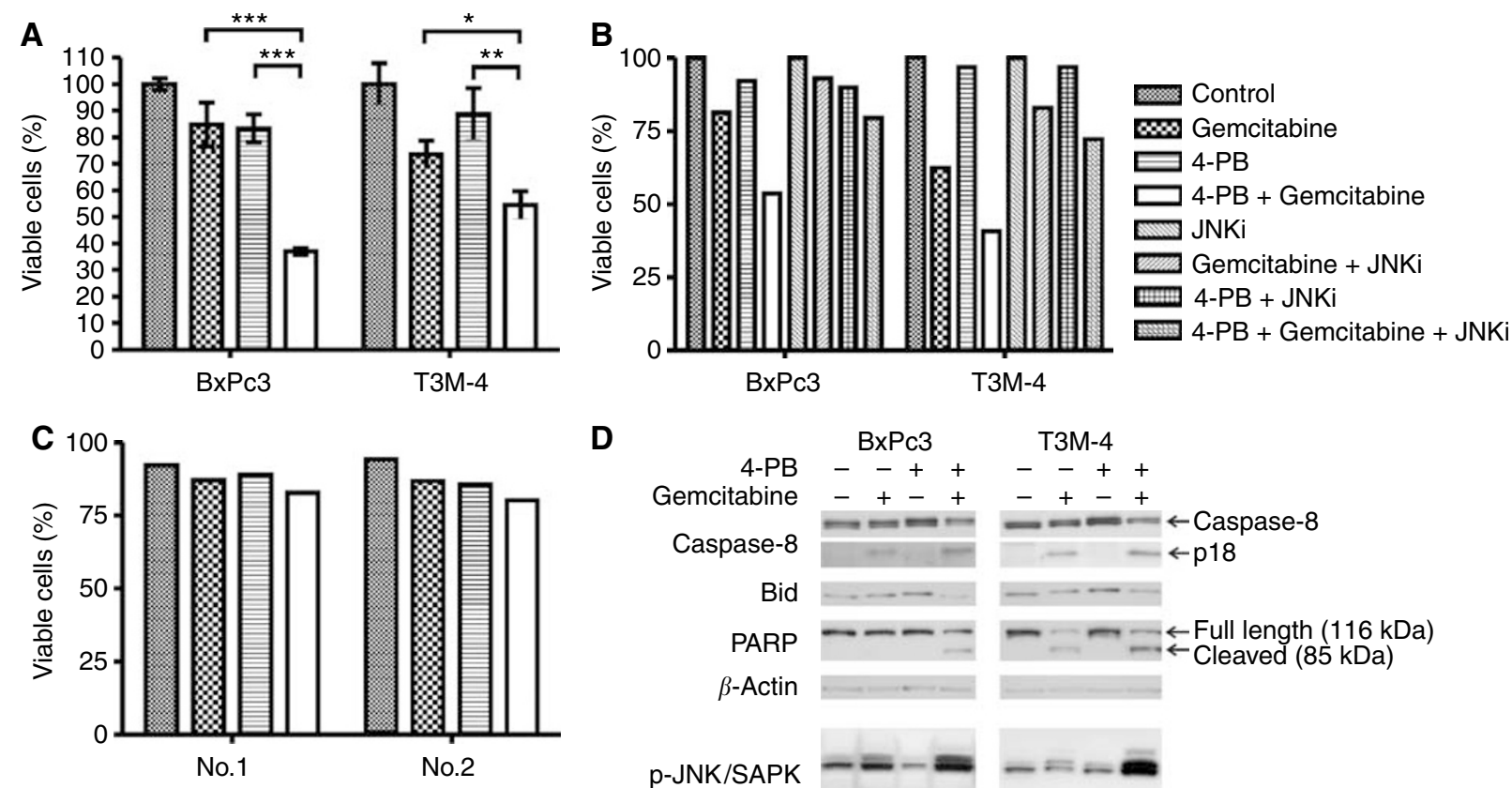

D

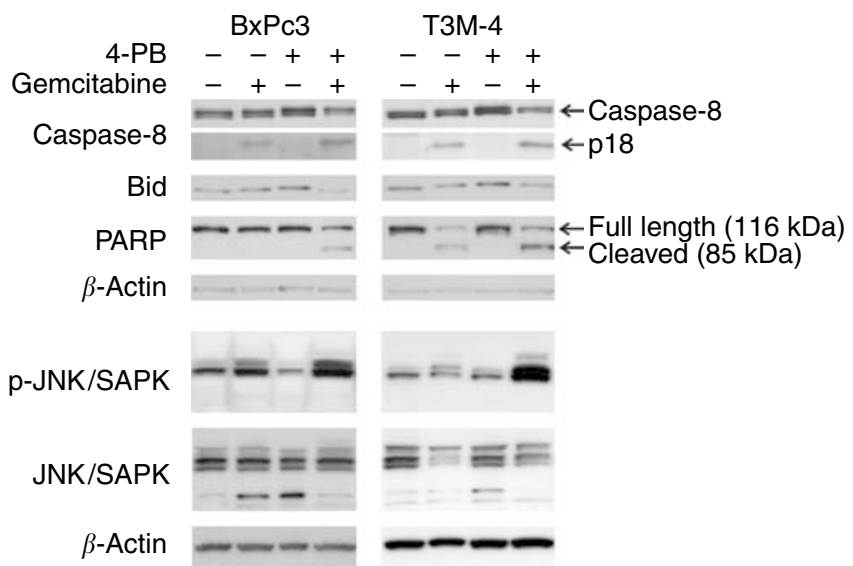

Figure 5 4-phenylbutyrate and gemcitabine induced apoptosis synergistically due to activation of Caspase 8 and BID in a JNK-pathway-dependent manner. (A) Cells were either not treated (fine dotted), treated with gemcitabine $\left(1.0 \mu \mathrm{g} \mathrm{ml} \mathrm{l}^{-1}\right.$, dotted), 4-PB ( $1.0 \mathrm{~mm}$, dashed) or gemcitabine and 4-PB simultaneously for $48 \mathrm{~h}$ and utilised for JAM assay. Mean and s.d of the number of viable cells (compared to control) from at least three experiments are shown. Differences between the single drug and the combinatorial treatment proved to be significant ( $t$-test). (B) BxPc3 or T3M-4 cells either not treated or treated with gemcitabine $\left(1.0 \mu \mathrm{g} \mathrm{ml}^{-1}\right)$, 4-PB (I.0 mM), JNKi (SP600 I25, inhibitor of c-Jun N-terminale kinase, $\left.20 \mu \mathrm{M}\right)$ or different combination of these drugs for $48 \mathrm{~h}$ as indicated in the legend were stained by annexin V/propidium iodide and employed for cell cytometry. Number of viable cells is presented. The gemcitabine-induced cell death (as single drug or in combination with 4-PB) could be inhibited by inhibition of JNK. (C) Peripheral blood mononuclear cells were isolated from two human donors (no. I and no. 2) as described in Materials and Methods. Cells were not treated or treated with gemcitabine, 4-PB or a combination of both for $20 \mathrm{~h}$. Cells were collected, stained by annexin V/propidium iodide and FACS analysis was conducted. The number of viable cells is presented. (D) After isolating proteins from BcPc3 or T3M-4 cells not treated (-) or treated $(+)$ with $1.0 \mathrm{mM} 4-\mathrm{PB}$ and/or $1.0 \mu \mathrm{g} \mathrm{ml}{ }^{-1}$ gemcitabine for $48 \mathrm{~h}$ $20 \mu \mathrm{g}$ protein were used to conduct Western blot analysis using specific antibodies against Caspase 8, Bid, PARP, phosphorylated JNK/SAPK, whole JNKI SAPK or $\beta$-actin as a control (p /8: cleaving product of Caspase 8 activation). 


\section{DISCUSSION}

In several current gene expression studies of pancreatic tumour cells, the authors have identified numerous genes differently expressed in tumour tissue compared to normal tissue (Crnogorac-Jurcevic et al, 2002; Iacobuzio-Donahue et al, 2003; Logsdon et al, 2003; Grutzmann et al, 2004) in order to identify possible therapeutic targets. But no key player whose expression could be modified in the context of a specific therapy has been identified yet.

Instead of addressing the expression of only one or few specific genes, drugs influencing general mechanisms of gene regulation could address the aberrant expression of various genes simultaneously (Sowa and Sakai, 2000). As low differentiation grades of carcinomas correlate with a bad prognosis, drugs inducing a differentiated phenotype could be a substantial benefit for patients with tumours like PDAC. Either single drug treatment itself, or more likely, combinatorial treatment with established anticancer regimens, might prove to be efficient by downregulating genes responsible for apoptosis resistance. Acetylation of histones, for example, by transcription factors induces changes in the chromatin structure and increases the accessibility of the DNA leading to gene activation. On the other hand, deacetylation of histones by HDAC inactivates gene expression (Kuo and Allis, 1998; Hess-Stumpp, 2005). Inhibitors of HDACs might be a promising additive in cancer therapy as they can activate numerous genes and thus might reactivate pathways controlling apoptosis, differentiation or growth control (Huang et al, 2000; Sowa and Sakai, 2000). The HDAC inhibitor 4-PB (Jung, 2001) belongs to the family of short fatty acids and is long used for treatment of inborn defects of the urea cycle. Patient suffering from this disease have been treated with 4-PB for years without major side effects at a similar dose that was used in this study (recommended treatment for urea cycle disorders: $3.0 \mathrm{~g} \mathrm{~kg}^{-1}$ bodyweight day ${ }^{-1}$ according to the manufacturer; http://www.tributyrate.com/html/urea_cycle_disorder.php).

Here, we demonstrated that 4-PB efficiently increases gap junction communications (GJCs) and inhibits cellular export mechanisms in PDAC cell lines along with overcoming drug resistance, induction of apoptosis and reduction of tumour cell numbers.

An induction of apoptosis upon 4-PB treatment is in agreement with studies showing this in cancer cell lines derived from other tumour entities like prostate cancer (Carducci et al, 1996), medulloblastoma (Li et al, 2004) or colon cancer (Feinman et al, 2002). Furthermore, in a rat model system 4-PB caused regression of tumours derived from hepatocarcinoma (Hep3B) or hepatoblastoma (HepT1) cells (Svechnikova et al, 2003).

Interestingly, we found that H6c7- cells, a pancreatic ductal epithelial cell line is also sensitive to 4-PB treatment with concentrations exceeding $2.0 \mathrm{~mm}$. Even if not from malignant origin and with nearly normal phenotype, these E6/E7 transformed cells (Furukawa et al, 1996; Ouyang et al, 2000) bear some characteristics of tumour cells like immortality and a high proliferation rate. Thus, our data support the idea that 4-PB acts not specifically on malignant but also on other highly proliferating immortalised cells. Low proliferating primary human fibroblasts and PBMC were not effected by 4-PB in the concentrations tested. Partly in contrast to other studies reporting a cell cycle arrest of tumour cells upon 4-PB treatment (DiGiuseppe et al, 1999; Clarke et al, 2001), only half of the cell lines investigated by us showed an arrest of the cell cycle in the G1-phase. This divergence namely of the PDAC cells might be explained by significant differences in the transcriptome of these cell lines (Grutzmann et al, 2004). It has been previously described that the cell cycle arrest in tumour cells upon 4-PB treatment depends on p21 (DiGiuseppe et al, 1999). Interestingly, according to a microarray-based study (Grutzmann et al, 2004), cells showing a cell cycle arrest in this study (T3M-4 and Colo357) express p21 to a higher extend than the nonarresting cells (Pancl and $\mathrm{BxPc} 3$ ). Whether this is indeed the reason for the differential behaviour upon the drug treatment or if other differentially expressed cell cycle regulators play a pivotal role remains to be shown.

Gap junctions are important for the transfer of small molecules between adjacent cells. The resulting intercellular communication is essential for both proliferation and activation of differentiation pathways (Seo et al, 2006). It has been shown that highly proliferating malignant cells have less gap junctions than more differentiated ones (Yamasaki and Naus, 1996). Interestingly, we found that $4-\mathrm{PB}$ increases GJC in PDAC similar to previous analyses in glioblastoma (Asklund et al, 2004). Besides the fact that $4-\mathrm{PB}$ already induces apoptosis of pancreatic carcinoma cells when applied as a single drug, the increase in GJC might allow an exchange of apoptotic signals between neighbouring cells. Furthermore, an increase in GJC is of benefit when additional anticancer drugs are administrated simultaneously and especially when bystander killing effects are important (Ammerpohl et al, 2004).

Upon chemotherapy tumour cells often gain resistance to established drugs. One way to achieve this resistance is the activation of export mechanisms. Cellular pumps like ABCG2, MDR1 or MRP1 can export a broad spectrum of molecules, including chemotherapeutics out of the cells (Glavinas et al, 2004; Katragadda et al, 2005), preventing them from killing the tumour cell. In this study, we could show that 4 -PB reduces the cellular export of calcein-AM in all cell lines tested. In the case of COLO 357 and $\mathrm{BxPc} 3$ cells, the inhibition by $4-\mathrm{PB}$ is even stronger than the one caused by verapamil, a known inhibitor of MDR1 (Hindenburg et al, 1987). Because concentrations of verapamil up to $500 \mu \mathrm{m}$ could not further inhibit cellular export in our experiment (data not shown) it is likely, that the verapamil concentration applied led already to a maximum inhibition of MDR1. Thus, the additional inhibition by 4-PB compared to verapamil is probably caused by the inhibition of additional or other cellular pumps than MDR1, which are not effected by verapamil. In contrast to verapamil, which as a 'classical' inhibitor caused maximum inhibition in less than $2 \mathrm{~h}$ (data not shown), 4PB needed at least $24 \mathrm{~h}$ to cause any inhibition of cellular export and furthermore this inhibition increased with the time of treatment. Because high activities of cellular transporters were found to be associated with low differentiation grades (e.g. like in stem cells) (Islam et al, 2005a, b), the decrease in cellular export caused by $4-\mathrm{PB}$ might be due to induction of differentiation. This would be supported by other reports describing the potential of 4$\mathrm{PB}$ to induce differentiation in tumour cells (Samid et al, 1997; Bar-Ner et al, 1999; Li et al, 2004). Thus, our findings that 4-PB increases the susceptibility of pancreatic carcinoma cells to apoptosis, that it increases intercellular communications and reduces cellular export makes 4-PB a promising drug for a combinatorial treatment with a 'classical' chemotherapeutical drug like gemcitabine or 5-FU, because higher differentiations grades are also associated with increased sensitivity to chemotherapy.

As gemcitabine is an established drug in the regimen against pancreatic adenocarcinoma, we combined this drug with 4-PB and tested the responsiveness of two pancreatic tumour cell lines $\mathrm{BxPC} 3$ and T3M-4. Most promising for future therapies, we found that 4-PB clearly potentiated gemcitabine-mediated cell death. Analysing the 4-PB-mediated sensitising effect, we demonstrated that 4-PB increased the expression of proapoptotic proteins Caspase- 8 and Bid and strongly enhanced the gemcitabinemediated activation of JNK. Although in other model systems like colon cancer or liver cancer induction of Caspase 3 by 4-PB treatment was described (Clarke et al, 2001; Svechnikova et al, 2003), we found only Caspase 8 to be upregulated.

Recently, it has been reported that high constitutive activity of $\mathrm{NF}-\kappa \mathrm{B}$ inhibits chemotherapeutic agent-mediated apoptosis in 
pancreatic tumour cells (Arlt et al, 2003). By using EMSA and NF- $\kappa$ B ELISA, we found no influence of $4-\mathrm{PB}$ on NF- $\kappa \mathrm{B}$ activity (data not shown). We conclude that 4-PB does not influence this antiapoptotic pathway. Instead, inhibition of JNK-activity by JNK inhibitor II not only partially reduced gemcitabine-mediated apoptosis but also completely abolished the sensitising effects of 4 -PB. This finding is in line with a recent study demonstrating the relevance of the JNK-pathway for apoptosis induction upon single drug 4-PB treatment in lung carcinoma cells (Zhang et al, 2004). In our model system, inhibition of the JNK-pathway primarily decreased the gemcitabine depending cell killing.

In contrast, Habiro et al (2004) showed that JNKs are not activated following gemcitabine treatment in pancreatic tumour cell lines PK-1 and PCI-43 and are dispensable for gemcitabineinduced apoptosis and in these cells. Instead, the authors postulated the involvement of p38 MAPK in this apoptotic pathway, the effects which we could not confirm in BxPC3 and T3M-4 cells, even using the same pharmacological inhibitor SB203580 (data not shown). These discrepancies may be explained by the cell lines used for investigations. Nevertheless, our results demonstrate that gemcitabine induces JNK in BxPC3 and T3M-4 cells and this effect is partially involved in gemcitabine-mediated cell death observed in these cells. Moreover, 4-PB strongly increases JNK-activity and this obviously represents one of the mechanisms by which 4-PB sensitises cells towards gemcitabine therapy.

Interestingly, the sensitising effects of 4-PB were observed in low concentration of both $4-\mathrm{PB}$ and gemcitabine and no significant further enhancement of apoptosis could be achieved neither by the increase of 4-PB concentration nor by the increase of gemcitabine (data not shown).

Highly relevant for the clinical use, 4-PB acts specifically on malignant cells, as non-malignant cells like primary human fibroblasts and PBMC were significantly less sensitive to this treatment. This important finding is supported by other authors showing the insensitivity of HBE4-E6/E7-cells, a non-transformed cell line, to 4-PB treatment (Zhang et al, 2004). This tolerance of non-malignant cells makes $4-\mathrm{PB}$ an interesting drug also in a combinatorial therapy with established chemotherapeutics where side effects would prevent a combination with other cytotoxic drugs.

4-phenylbutyrate has been shown to have additional anticancer effects non-related to HDAC inhibition, for example, by inducing glutamine depletion (Darmaun et al, 1998). Even if we cannot rule out similar effects in pancreatic cancer cells, which could also contribute to the anticancer effect of the drug, a major contribution to the chemosensitising effect of 4-PB is very likely given by the inhibition of HDAC activity. The inhibition of HDAC activity probably induces changes in the expression of genes involved in cellular export mechanisms or GJC. This is also supported by findings in erythroleukemia cells and human leukaemic cells (Lea et al, 1999) denying a growth inhibitory effect depended on glutamine depletion upon 4-PB treatment. Further own findings by RT - PCR analysis showing an upregulation of tumour suppressor genes like fgfr2 or a downregulation of oncogenes like gadd $45 \mathrm{~b}, \mathrm{ccnb} 1$, cflar or cdc25b in pancreatic cancer cells upon 4-PB treatment (data not shown) argue also for the involvement of general transcription regulating mechanisms like chromatin modifications, as these genes have been previously described to be deregulated in PDAC (Grutzmann et al, 2004).

Taken together, these findings provide evidence that the welltolerated and FDA-approved drug 4-PB (Rubenstein and Zeitlin, 1998 ) is to be seen as a promising supplemental therapeutic agent for the treatment of PDAC patients.

\section{ACKNOWLEDGEMENTS}

This work was supported by grants from the Deutsche Krebshilfe (70-2937-SaI) and the Kreitz-Stiftung. AT was supported by SFB415/project A3, a DFG-grant given to HK. HPDE6-E6E7-c7 cells were kindly provided by Dr M-S Tsao (UHN, Toronto, Canada). We thank P Heide for her excellent technical assistance and $\mathrm{H}$ Boigs for his additional support.

\section{REFERENCES}

Ammerpohl O, Thormeyer D, Khan Z, Appelskog IB, Gojkovic Z, Almqvist PM, Ekstrom TJ (2004) HDACi phenylbutyrate increases bystander killing of HSV-tk transfected glioma cells. Biochem Biophys Res Commun 324: $8-14$

Arlt A, Gehrz A, Muerkoster S, Vorndamm J, Kruse ML, Folsch UR, Schafer $\mathrm{H}$ (2003) Role of NF-kappaB and Akt/PI3K in the resistance of pancreatic carcinoma cell lines against gemcitabine-induced cell death. Oncogene 22: $3243-3251$

Asklund T, Appelskog IB, Ammerpohl O, Ekstrom TJ, Almqvist PM (2004) Histone deacetylase inhibitor 4-phenylbutyrate modulates glial fibrillary acidic protein and connexin 43 expression, and enhances gap-junction communication, in human glioblastoma cells. Eur J Cancer 40: $1073-1081$

Bar-Ner M, Thibault A, Tsokos M, Magrath IT, Samid D (1999) Phenylbutyrate induces cell differentiation and modulates Epstein-Barr virus gene expression in Burkitt's lymphoma cells. Clin Cancer Res 5: $1509-1516$

Bengala C, Guarneri V, Giovannetti E, Lencioni M, Fontana E, Mey V, Fontana A, Boggi U, Del Chiaro M, Danesi R, Ricci S, Mosca F, Del Tacca M, Conte PF (2005) Prolonged fixed dose rate infusion of gemcitabine with autologous haemopoietic support in advanced pancreatic adenocarcinoma. Br J Cancer 93: 35-40

Bhalla K, List A (2004) Histone deacetylase inhibitors in myelodysplastic syndrome. Best Pract Res Clin Haematol 17: 595-611

Carducci MA, Nelson JB, Chan-Tack KM, Ayyagari SR, Sweatt WH, Campbell PA, Nelson WG, Simons JW (1996) Phenylbutyrate induces apoptosis in human prostate cancer and is more potent than phenylacetate. Clin Cancer Res 2: 379-387
Clarke KO, Feinman R, Harrison LE (2001) Tributyrin, an oral butyrate analogue, induces apoptosis through the activation of caspase-3. Cancer Lett 171: 57-65

Crnogorac-Jurcevic T, Efthimiou E, Nielsen T, Loader J, Terris B, Stamp G, Baron A, Scarpa A, Lemoine NR (2002) Expression profiling of microdissected pancreatic adenocarcinomas. Oncogene 21: 4587-4594

Darmaun D, Welch S, Rini A, Sager BK, Altomare A, Haymond MW (1998) Phenylbutyrate-induced glutamine depletion in humans: effect on leucine metabolism. Am J Physiol 274: E801-E807

DiGiuseppe JA, Weng LJ, Yu KH, Fu S, Kastan MB, Samid D, Gore SD (1999) Phenylbutyrate-induced G1 arrest and apoptosis in myeloid leukemia cells: structure-function analysis. Leukemia 13: $1243-1253$

Eisenberg DP, Adusumilli PS, Hendershott KJ, Yu Z, Mullerad M, Chan MK, Chou TC, Fong Y (2005) 5-fluorouracil and gemcitabine potentiate the efficacy of oncolytic herpes viral gene therapy in the treatment of pancreatic cancer. J Gastrointest Surg 9: 1068-1077; discussion $1077-1079$

Feinman R, Clarke KO, Harrison LE (2002) Phenylbutyrate-induced apoptosis is associated with inactivation of NF-kappaB IN HT-29 colon cancer cells. Cancer Chemother Pharmacol 49: 27-34

Furukawa T, Duguid WP, Rosenberg L, Viallet J, Galloway DA, Tsao MS (1996) Long-term culture and immortalization of epithelial cells from normal adult human pancreatic ducts transfected by the E6E7 gene of human papilloma virus 16. Am J Pathol 148: $1763-1770$

Gelibter A, Malaguti P, Di Cosimo S, Bria E, Ruggeri EM, Carlini P, Carboni F, Ettorre GM, Pellicciotta M, Giannarelli D, Terzoli E, Cognetti F, Milella M (2005) Fixed dose-rate gemcitabine infusion as first-line treatment for 
advanced-stage carcinoma of the pancreas and biliary tree. Cancer 104: $1237-1245$

Glavinas H, Krajcsi P, Cserepes J, Sarkadi B (2004) The role of ABC transporters in drug resistance, metabolism and toxicity. Curr Drug Deliv 1: $27-42$

Grutzmann R, Pilarsky C, Ammerpohl O, Luttges J, Bohme A, Sipos B, Foerder M, Alldinger I., Jahnke B, Schackert HK, Kalthoff H, Kremer B, Kloppel G, Saeger HD (2004) Gene expression profiling of microdissected pancreatic ductal carcinomas using high-density DNA microarrays. Neoplasia 6: 611-622

Habiro A, Tanno S, Koizumi K, Izawa T, Nakano Y, Osanai M, Mizukami Y, Okumura T, Kohgo Y (2004) Involvement of p38 mitogen-activated protein kinase in gemcitabine-induced apoptosis in human pancreatic cancer cells. Biochem Biophys Res Commun 316: 71-77

Hess-Stumpp H (2005) Histone deacetylase inhibitors and cancer: from cell biology to the clinic. Eur J Cell Biol 84: 109-121

Hindenburg AA, Baker MA, Gleyzer E, Stewart VJ, Case N, Taub RN (1987) Effect of verapamil and other agents on the distribution of anthracyclines and on reversal of drug resistance. Cancer Res 47: 1421 - 1425

Huang L, Sowa Y, Sakai T, Pardee AB (2000) Activation of the p21WAF1/ CIP1 promoter independent of p53 by the histone deacetylase inhibitor suberoylanilide hydroxamic acid (SAHA) through the Sp1 sites. Oncogene 19: 5712-5719

Iacobuzio-Donahue CA, Maitra A, Olsen M, Lowe AW, van Heek NT, Rosty C, Walter K, Sato N, Parker A, Ashfaq R, Jaffee E, Ryu B, Jones J, Eshleman JR, Yeo CJ, Cameron JL, Kern SE, Hruban RH, Brown PO, Goggins M (2003) Exploration of global gene expression patterns in pancreatic adenocarcinoma using cDNA microarrays. Am J Pathol 162: $1151-1162$

Islam MO, Kanemura Y, Tajria J, Mori H, Kobayashi S, Hara M, Yamasaki M, Okano H, Miyake J (2005a) Functional expression of ABCG2 transporter in human neural stem/progenitor cells. Neurosci Res 52: $75-82$

Islam MO, Kanemura Y, Tajria J, Mori H, Kobayashi S, Shofuda T, Miyake J, Hara M, Yamasaki M, Okano H (2005b) Characterization of ABC transporter ABCB1 expressed in human neural stem/progenitor cells. FEBS Lett 579: 3473 - 3480

Jemal A, Murray T, Ward E, Samuels A, Tiwari RC, Ghafoor A, Feuer EJ, Thun MJ (2005) Cancer statistics, 2005. CA Cancer J Clin 55: 10-30

Jung M (2001) Inhibitors of histone deacetylase as new anticancer agents. Curr Med Chem 8: $1505-1511$

Karaszi E, Jakab K, Homolya L, Szakacs G, Hollo Z, Telek B, Kiss A, Rejto L, Nahajevszky S, Sarkadi B, Kappelmayer J (2001) Calcein assay for multidrug resistance reliably predicts therapy response and survival rate in acute myeloid leukaemia. Br J Haematol 112: 308-314

Katragadda S, Budda B, Anand BS, Mitra AK (2005) Role of efflux pumps and metabolising enzymes in drug delivery. Expert Opin Drug Deliv 2: $683-705$

Kim YH, Park JW, Lee JY, Kwon TK (2004) Sodium butyrate sensitizes TRAIL-mediated apoptosis by induction of transcription from the DR5 gene promoter through Sp1 sites in colon cancer cells. Carcinogenesis 25: $1813-1820$

Ko AH, Tempero MA (2005) Systemic therapy for pancreatic cancer. Semin Radiat Oncol 15: $245-253$

Kuo MH, Allis CD (1998) Roles of histone acetyltransferases and deacetylases in gene regulation. Bioessays 20: 615-626

Lea MA, Randolph VM, Hodge SK (1999) Induction of histone acetylation and growth regulation in eryrthroleukemia cells by 4-phenylbutyrate and structural analogs. Anticancer Res 19: 1971 - 1976

Li XN, Parikh S, Shu Q, Jung HL, Chow CW, Perlaky L, Leung HC, Su J, Blaney S, Lau CC (2004) Phenylbutyrate and phenylacetate induce differentiation and inhibit proliferation of human medulloblastoma cells. Clin Cancer Res 10: $1150-1159$
Logsdon CD, Simeone DM, Binkley C, Arumugam T, Greenson JK, Giordano TJ, Misek DE, Kuick R, Hanash S (2003) Molecular profiling of pancreatic adenocarcinoma and chronic pancreatitis identifies multiple genes differentially regulated in pancreatic cancer. Cancer Res 63: $2649-2657$

Nakano K, Mizuno T, Sowa Y, Orita T, Yoshino T, Okuyama Y, Fujita T, Ohtani-Fujita N, Matsukawa Y, Tokino T, Yamagishi H, Oka T, Nomura H, Sakai T (1997) Butyrate activates the WAF1/Cip1 gene promoter through Sp1 sites in a p53-negative human colon cancer cell line. J Biol Chem 272: 22199-22206

Ouyang H, Mou L, Luk C, Liu N, Karaskova J, Squire J, Tsao MS (2000) Immortal human pancreatic duct epithelial cell lines with near normal genotype and phenotype. Am J Pathol 157: 1623-1631

Phuphanich S, Baker SD, Grossman SA, Carson KA, Gilbert MR, Fisher JD, Carducci MA (2005) Oral sodium phenylbutyrate in patients with recurrent malignant gliomas: a dose escalation and pharmacologic study. Neuro-oncology 7: 177-182

Pipas JM, Barth RJ, Jr, Zaki B, Tsapakos MJ, Suriawinata AA, Bettmann MA, Cates JM, Ripple GH, Sutton JE, Gordon SR, McDonnell CE, Perez RP, Redfield N, Meyer LP, Marshall JF., Cole BF, Colacchio TA (2005) Docetaxel/Gemcitabine followed by gemcitabine and external beam radiotherapy in patients with pancreatic adenocarcinoma. Ann Surg Oncol 12: 995 - 1004

Rubenstein RC, Zeitlin PL (1998) A pilot clinical trial of oral sodium 4phenylbutyrate (Buphenyl) in deltaF508-homozygous cystic fibrosis patients: partial restoration of nasal epithelial CFTR function. Am J Respir Crit Care Med 157: 484-490

Samid D, Hudgins WR, Shack S, Liu L, Prasanna P, Myers CE (1997) Phenylacetate and phenylbutyrate as novel, nontoxic differentiation inducers. Adv Exp Med Biol 400A: 501-505

Seo MS, Park JS, Yang SR, Park KS, Hong IS, Jo EH, Kang KS, Lee YS (2006) Expression of MAP kinases and connexins in the differentiation of rat mammary epithelial cells. J Vet Med Sci 68: 567-571

Sipos B, Moser S, Kalthoff H, Torok V, Lohr M, Kloppel G (2003) A comprehensive characterization of pancreatic ductal carcinoma cell lines: towards the establishment of an in vitro research platform. Virchows Arch 442: $444-452$

Sowa Y, Sakai T (2000) Butyrate as a model for 'gene-regulating chemoprevention and chemotherapy. Biofactors 12: 283-287

Svechnikova I, Gray SG, Kundrotiene J, Ponthan F, Kogner P, Ekstrom TJ (2003) Apoptosis and tumor remission in liver tumor xenografts by 4phenylbutyrate. Int J Oncol 22: 579-588

Trauzold A, Schmiedel S, Roder C, Tams C, Christgen M, Oestern S, Arlt A, Westphal S, Kapischke M, Ungefroren H, Kalthoff H (2003) Multiple and synergistic deregulations of apoptosis-controlling genes in pancreatic carcinoma cells. $\mathrm{Br}$ J Cancer 89: $1714-172$

Ungefroren H, Voss M, Jansen M, Roeder C, Henne-Bruns D, Kremer B, Kalthoff H (1998) Human pancreatic adenocarcinomas express Fas and Fas ligand yet are resistant to Fas-mediated apoptosis. Cancer Res 58: $1741-1749$

Yamasaki H, Naus CC (1996) Role of connexin genes in growth control. Carcinogenesis 17: $1199-1213$

Yokota N, Mainprize TG, Taylor MD, Kohata T, Loreto M, Ueda S, Dura W, Grajkowska W, Kuo JS, Rutka JT (2004) Identification of differentially expressed and developmentally regulated genes in medulloblastoma using suppression subtraction hybridization. Oncogene 23: $3444-3453$

Yoshida M, Furumai R, Nishiyama M, Komatsu Y, Nishino N, Horinouchi S (2001) Histone deacetylase as a new target for cancer chemotherapy. Cancer Chemother Pharmacol 48(Suppl 1): S20-S26

Zhang X, Wei L, Yang Y, Yu Q (2004) Sodium 4-phenylbutyrate induces apoptosis of human lung carcinoma cells through activating JNK pathway. J Cell Biochem 93: 819-829 